\title{
Research and Practice of Quantitative Models on The Freedom of Trade Based on AHP-FCE Method: Taking Major Countries in WTO as Examples
}

\author{
Qin Sishi ${ }^{1, a}$, Tang Ji'an²,b ${ }^{2}$ Liu Feng ${ }^{3, c *}$, Shao Shuqian ${ }^{4, d}$, Lu Shiying $^{5, \mathrm{e}}$ \\ ${ }^{1}$ Shanghai University of International, Business and Economics, Shanghai China \\ ${ }^{2}$ Shanghai University of International, Business and Economics, Shanghai China \\ ${ }^{3}$ Institute of Artificial Intelligence and Change Management/Shanghai University of International Business and Economics, Shanghai \\ China \\ ${ }^{4}$ Shanghai University of International, Business and Economics, Shanghai China \\ ${ }^{5}$ Changsha university of science and technology, Hunan China
}

\begin{abstract}
In recent years, protectionism and unilateralism in the field of international trade are increasing. The WTO-centric multilateral trade regime has been hit. By researching the index of trade freedom among countries in international trade, this paper takes five important countries in WTO as an example, and constructs the trade freedom index and the national trade freedom model. The study reviewed and analysed global and regional developments in cross-border trade and investigated five varialbes that impacted the index of trade freedom. Then the fuzzy comprehensive analysis method (FCE) is used to obtain the comprehensive evaluation matrix by fuzzy arithmetic processing through the evaluation index weight and fuzzy relation matrix. Therefore, the changing data of the index of trade freedom in five countries from 2017 to 2018 are obtained. It is discovered that there is a significant difference in the index of trade freedom among countries. What's worse, the average of the global index has declined year by year. This phenomenon is caused by the decline of global trade volume and the prevalence of new trade barriers. In the end, this paper proposes the implementation of multilateral negotiations and the establishment of long-term penalties as possible solutions.
\end{abstract}

\section{Introduction}

With the development of science and technology, economic relations between countries are becoming closer. However, all kinds of bilateral and multilateral free-trade agreements emerge endlessly with the development of protectionism and unilateralism in the field of international trade. Many scholars have researched how to measure a country's freedom of trade. In economic statistics, foreign trade ratio represents the freedom of trade. The formula is defined as gross import and export divided by GDP. ${ }^{[1]}$ But this definition does not take the level of economic development and the size of the population into account. In addition, it overlooked the impact of trade, exchange rate policies and other variables on trade freeness.

To this end, this paper uses the AHP-FCE method to weigh the indicators in a comprehensive review of countries' trade-freeness. Then, based on the comprehensive scores and the scores of the various indicators, we clustered the data to give a general overview of the trade freedom of each country.

\section{Principal and comprehensive evaluation of index of trade freedom by ahp-fce method}

\subsection{Variables Selection (Evaluation Factor Set):}

Trade-freeness will be researched about the economic impact of one country. However, there are many criteria about the trade-freeness. Hence, this paper will refer to the World Bank's openness criteria and quantitative assessment of economic freedom by the American Heritage Foundation, and set multi-dimensional evaluation standards. At the same time, this paper will measure based on personal choice, voluntary exchange, free market access and fair competition, and protection of persons and property against unlawful infringement. We will focus on five variables as the table below. Also this paper establishes the evaluation factors set:

$$
U=\left\{u_{1}, u_{2}, u_{3}, u_{4}, u_{5}\right\}
$$

a1034109212@qq.com, b2513217525@qq.com, ${ }^{\mathrm{c} l s t t o y @ 163 . c o m, ~}{ }^{\mathrm{d} A n i a}$ Vort@163.com, ${ }^{\mathrm{e} 529455452 @ q q . c o m}$ 
TABLE I. TRADE FREEDOM FACTOR SET

\begin{tabular}{ll}
\hline $\boldsymbol{u}_{1}$ & Tax-rate of import and export \\
\hline $\boldsymbol{u}_{\mathbf{2}}$ & $\begin{array}{l}\text { Degree of participation in } \\
\text { WTO }\end{array}$ \\
\hline $\boldsymbol{u}_{\mathbf{3}}$ & Policy support index \\
\hline $\boldsymbol{u}_{\mathbf{4}}$ & National transportation grade \\
\hline $\boldsymbol{u}_{\mathbf{5}}$ & National GDP per capita \\
\hline
\end{tabular}

\subsubsection{Tax-rate of import and export}

Import and export tariff rate is an important indicator of the openness of a country. This paper will use world tariff rates (data from the collation of data from the World Bank's public database).

\subsubsection{Degree of participation in WTO}

The measure of a country's freedom of trade should not only be considered from the point of view of import and export trade tariffs and non-tariff barriers, but also take into account its participation in WTO and the free trade agreements signed. The degree of trade liberalization of a country is closely related to its participation in the World Trade Organization.

\subsubsection{Policy support index}

In history and reality, real free trade only appealed in certain periods and countries. ${ }^{[2]}$ In fact, the level of a country's foreign trade opening is in accordance with the principles of national interests. Thus, a country's policies have a profound impact on the freedom of international trade.

\subsubsection{National concumption grade}

Different levels of consumption and the change of consumption concept are also the important reasons. ${ }^{[3]}$ Taking China as an example, since the 20th century, the people's level of consumer awareness has been increasing. In addition, the demand for specific goods is no longer satisfied with the supply of domestic goods, resulting in a reverse inflow of goods with original comparative advantages in trade. ${ }^{[4]}$ Therefore, the increase of demand for foreign goods stimulates the trade openness of the country.

\subsubsection{National GDP per capita}

GDP per capita influences international trade flows the most. ${ }^{[5]}$ The quality of a country's economic growth and the improvement of residents' income levels directly affect the scale of international trade. ${ }^{[6]}$ Countries with higher GDP per capita have higher purchasing power and demand for foreign goods.

\subsection{Data processing of index of trade freedom by AHP -FCE method}

\subsubsection{Identify the Comment Set}

Higher index of trade freedom depends on the lower the tariff rate on import and export trade. On the contrary, the greater degree of participation in the WTO, the degree to which the government encourages free trade, the level of national consumption, and the level of per capita GDP are better. Here we first grade the indicators and establish comment set:

$$
V=\left\{v_{1}, v_{2}, v_{3}\right\}
$$

The classification principle is as follows: the index of each country is sorted according to the order from small to large. And then we calculated the difference of the number of adjacent index. The two values with the largest difference are selected as the dividing points. ${ }^{[7]}{ }^{[8]}$ Then we take the average of the two points of demarcation as the classification standard. The following table shows some of the country's indicators affecting trade-freeness.

TABLE II. INDICATORS OF TRADE FREEDOM IN FIVE COUNTRIES IN 2018

\begin{tabular}{llllll}
\hline Indicators & $\begin{array}{l}\text { Tariff } \\
\text { rate } \\
(\mathbf{\% )}\end{array}$ & $\begin{array}{l}\text { Participation } \\
\text { in WTO } \\
(\mathbf{1 0 0})\end{array}$ & $\begin{array}{l}\text { Policy } \\
\text { Support } \\
(\mathbf{1 0 0 )}\end{array}$ & $\begin{array}{l}\text { National } \\
\text { consumption } \\
\text { index (100) }\end{array}$ & $\begin{array}{l}\text { Per capita } \\
\text { GDP (\$) }\end{array}$ \\
\hline Canada & 0.8 & 86 & 80 & 75 & 47535 \\
United & 2.4 & 68 & 76 & 85 & 61687 \\
States & & & & & \\
China & 3.5 & 71.8 & 73 & 57 & 9376 \\
India & 6.5 & 51 & 40 & 30 & 1989 \\
Brazil & 8 & 69 & 41 & 60 & 10514 \\
\hline
\end{tabular}

To confirm the comment set, here we will calculation the detail data. For the tariff rate, we find the two largest differences 0.8 and 8 . For the degree of participation in the WTO, we find the two largest differences 51 and 86 . For the degree to which the government encourages free trade, we find the two largest differences 40 and 80 . For the national consumption level, we find the two largest differences 30 and 85; and for the national per capita GDP level, we find the two largest differences 1989 and 61687.

The criteria for the indicators are as follows:. 
TABLE III. INDICATOR CLUSTERS

\begin{tabular}{llll}
\hline Indicators & \multicolumn{1}{c}{$\boldsymbol{v}_{\mathbf{1}}$} & \multicolumn{1}{c}{$\boldsymbol{v}_{\mathbf{2}}$} & \multicolumn{1}{c}{$\boldsymbol{v}_{\mathbf{3}}$} \\
\hline Import tariff rate (\%) & $\mathrm{X}>5$ & $2<\mathrm{x}<=5$ & $\mathrm{X}<=2$ \\
Participation in WTO (100) & $\mathrm{X}<=30$ & $30<\mathrm{X}<=60$ & $\mathrm{X}>60$ \\
Policy Support (100) & $\mathrm{X}<=40$ & $40<\mathrm{X}<=60$ & $\mathrm{X}>60$ \\
National consumption index (100) & $\mathrm{X}<=40$ & $40<\mathrm{X}<=60$ & $\mathrm{X}>60$ \\
National per capita GDP (\$) & $\mathrm{X}<=8000$ & $8000<\mathrm{X}$ & $\mathrm{X}>20000$ \\
& & $<=20000$ & \\
\hline
\end{tabular}

\subsubsection{Evaluation Matrix}

There are 5 factors and 3 classes in this model, and according to the comment set, we establish the detail evaluation matrix as follow:

$$
R=\left[\begin{array}{l}
r_{1} \\
r_{2} \\
r_{3} \\
r_{4} \\
r_{5}
\end{array}\right]=\left[\begin{array}{ccc}
0.4 & 0.4 & 0.2 \\
0 & 0.2 & 0.8 \\
0.2 & 0.2 & 0.6 \\
0.2 & 0.4 & 0.4 \\
0.2 & 0.4 & 0.4
\end{array}\right]
$$

\subsubsection{Determination of Weight Vector Based on AHP}

In order to further consider the influence of each factor, we use the analytic hierarchy process to measure the weight of each variable and compare the five indexes in pairs to establish the judgment matrix. We find the eigenvalues and eigenvectors of the judgment matrix, and then carry on the consistency test. The weight vector corresponding to the five indexes is:

$$
w=\{0.43,0.26,0.11,0.12,0.08\}
$$

\subsubsection{Weighted evaluation matrix:}

$$
T=w \times R=\left[\begin{array}{ccc}
0.172 & 0.172 & 0.086 \\
0 & 0.052 & 0.208 \\
0.022 & 0.022 & 0.066 \\
0.024 & 0.048 & 0.048 \\
0.016 & 0.032 & 0.032
\end{array}\right]
$$

\subsubsection{Fuzzy Comprehensive Score}

$$
B=\left[\begin{array}{lll}
1 & 2 & 3
\end{array}\right]
$$

The comprehensive scoring coefficient is:

$$
\text { Score }=T \times B^{T}
$$

\subsection{Comprehensive evaluation of trade freedom and ranking of countries}

We use Matlab to find the score of the five indexes that affect the trade freedom of each country and the comprehensive score level of the trade freedom. Then we use the cluster analysis to divide the national trade freedom into four categories roughly, and combine the two-year situation to divide it. Some of the results are as follows:

TABLE IV. COMPREHENSIVE EVALUATION OF TRADE FREEDOM AND RANKING OF COUNTRIES IN 2018

\begin{tabular}{lccccccc}
\hline Countries & $\boldsymbol{u}_{\mathbf{1}}$ & $\boldsymbol{u}_{\mathbf{2}}$ & $\boldsymbol{u}_{\mathbf{3}}$ & $\boldsymbol{u}_{\mathbf{4}}$ & $\boldsymbol{u}_{\mathbf{5}}$ & Level & Scores \\
\hline Canada & 0.43 & 0.25 & 0.17 & 0.06 & 0.08 & $\mathrm{~B}$ & 3.26 \\
United States & 0.31 & 0.20 & 0.28 & 0.19 & 0.07 & $\mathrm{~B}$ & 3.59 \\
China & 0.35 & 0.21 & 0.24 & 0.17 & 0.05 & $\mathrm{~B}$ & 3.38 \\
India & 0.23 & 0.12 & 0.21 & 0.12 & 0.03 & $\mathrm{D}$ & 2.42 \\
Brazil & 0.30 & 0.17 & 0.20 & 0.13 & 0.04 & $\mathrm{C}$ & 2.97 \\
\hline
\end{tabular}

TABLE V. COMPREHENSIVE EVALUATION OF TRADE FREEDOM AND RANKING OF COUNTRIES IN 2017

\begin{tabular}{lccccccc}
\hline Countries & $\boldsymbol{u}_{\mathbf{1}}$ & $\boldsymbol{u}_{\mathbf{2}}$ & $\boldsymbol{u}_{\mathbf{3}}$ & $\boldsymbol{u}_{\mathbf{4}}$ & $\boldsymbol{u}_{\mathbf{5}}$ & Level & Scores \\
\hline Canada & 0.42 & 0.25 & 0.13 & 0.09 & 0.07 & $\mathrm{~B}$ & 3.46 \\
United States & 0.37 & 0.22 & 0.28 & 0.19 & 0.07 & $\mathrm{~B}$ & 3.60 \\
China & 0.40 & 0.23 & 0.24 & 0.17 & 0.05 & $\mathrm{~B}$ & 3.30 \\
India & 0.21 & 0.12 & 0.21 & 0.12 & 0.03 & $\mathrm{D}$ & 2.58 \\
Brazil & 0.32 & 0.17 & 0.21 & 0.13 & 0.04 & $\mathrm{C}$ & 2.60 \\
\hline
\end{tabular}




\section{Discussion}

In the 1980s, the main measure of trade freedom index was the index. Dollars (1992) ${ }^{[9]}$ incorporates trade policy into trade freedom considerations, using the degree of deviation of the real price of goods from the price under trade opening conditions to calculate trade freedom. As global economic openness has generally increased, Harrison (1996) [10] and Patrick (1998) ${ }^{[11]}$ used the regression equation method to calculate the trade openness index and compare the gap between the actual value and the theoretical value to measure a country's trade freedom more comprehensively. Nevertheless, the above models are basically based on subjective evaluation. Although the disadvantage of ignoring the level of economic development and population size are solved, the specific impact of the effect could not be eliminated.

This paper uses the AHP-FCE method to weight the index, which carries on the comprehensive appraisal to each country trade-freeness. From the results, we can find that there are significant differences among countries in the index of trade freedom and the factors contributing to the differences are as follows:

\subsection{International trade growth is expected to decline}

WTO expects a 1.2 percent increase in global merchandise trade in 2019, the lowest level since 2009. Moreover, the WTO expects the growth rate to drop from 3.0 per cent to 2.7 in 2020 . The trade downside risks remain high, and the 2020 forecast depends on the process of normalizing trade relations.

\subsection{The status of regional free trade agreements highlights the serious challenges to the multilateral trade framework of the WTO}

With the rise of trade unilateralism and protectionism, the dominance of regional trade agreements highlights the serious challenges to the multilateral trade framework represented by the WTO.

\subsection{The prevalence of new trade barriers}

The trade protectionism is becoming more and more intense, and all kinds of new trade barriers are becoming prosperous. These new barriers take technical barriers as the core, covering safety standards, health standards, packaging marking, information technology standards, environmental marking, labor safety standards, welfare standards. Under the influence of these new trade barriers, some countries are constantly changing their ways to protect their domestic industries by adopting trade remedies permitted by the WTO, such as anti-dumping and anti-subsidy.

\section{Conclusion}

This paper comprehensively scores the trade-freeness of various countries and uses AHP method to weight the indicators based on the fuzzy comprehensive evaluation
(FCE). There are 5 factors and 3 classes in this model, and according to the comment set, we establish the detail evaluation matrix. We find that it has been greatly varied in the index of trade freedom among countries.In addition, the global average index of trade freedom has declined year by year because of regional protectionism.

On the basis of mutual respect and benefit, it is suggested that countries should give priority to resolving issues that threaten the sustainability of the WTO, instead of pursuing unrealistic standards such as zero tariffs, zero barriers and zero subsidies in one step. The existing WTO dispute settlement mechanism is an important force to maintain the multilateral trading system, but some members often use it for their own purposes. Therefore, the implementation of multilateral negotiations is a trend of WTO reform. At the same time, the establishment of efficient punishment measures is also one of the effective solutions.

However, this paper does not carry out in-depth analysis on all countries in the world. In the next research, we will analyze statistics compiled on nearly a decade of global data. This analysis will focus on regional trade and provide theoretical support and advice for the development of regional free trade.

\section{Acknowledgment}

This paper was supported by National Natural Science Foundation of China(72042004).

\section{References}

1. Tsurumi, Tetsuya, \& Managi, Shunsuke. The effect of trade openness on deforestation: empirical analysis for 142 countries. Environmental Economics \& Policy Studies, 16(4), 305-324.

2. Cheng B.Y(2017) Impact of national policy on international trade [J]. Business Situation, 2017(10).

3. Huchetâ M. \& Vijil M. (2018). The relationship between trade openness and economic growth: some new insights on the openness measurement issue. World Economy, 41.

4. Yan H.X(2015). On the Influence of the Change of Public Consumption Consciousness on International Trade -- An Analysis of Multi-product Multi-factor Comparative Advantage Model [J]. Market Modernization,2015(05):14-15.

5. Mireku, K., Agyei, E. A., \& Domeher, D. (2018). Trade openness and economic growth volatility: an empirical investigation.

6. E. Glen Weyl. (2018). The openness and quality trade in global redistribution. Social Science Electronic Publishing, 128.

7. Kim, K., Altmann, J., \& Hwang, J. (2010). Measuring and Analyzing the Openness of the Web2.0 Service Network for Improving the Innovation Capacity of the Web2.0 System through Collective Intelligence. On Collective Intelligence. 
8. Ventura B. \& Laia. (2006). Trade openness and preferences for redistribution: a cross-national assessment of the compensation hypothesis. Business and Politics, 8(2).

9. Dollar D. (1992). Outward-oriented developing economies really do grow more rapidly: evidence from 95 ldcs, 1976-1985. Economic Development \& Cultural Change, 40(3), 523-544
10. Harrison A. (1996) "Openness and growth: a time series, cross country analysis for developing Countries", Journal of Development Economics, Vol48, 419-447

11. Patrick L.\& Marcelo O.(1998) "Does Globalization Cause a Higher Concentration of International Trade and Investment Flow?" 